\title{
VIDEO TUTORIAL SENI LUKIS AQUAREL SEBAGAI MEDIA PENYAMPAIAN MATERI WORKSHOP DI KELAS EKSTRAKURIKULER SEKOLAH FORMAL
}

\author{
Muhammad Faizal Agung Nugroho \\ Institut Manajemen Wiyata Indonesia, Sukabumi \\ Indonesia \\ Email: komostudio80@gmail.com
}

\begin{abstract}
Abstrak
Sebagai lembaga pendidikan, sekolah sebenarnya mampu mengembangkan dan meningkatkan kemampuan akademik siswa maupun non-akademis. Salah satu pendidikan non-akademis yang sering diajarkan disekolah merupakan Pendidikan seni yang mampu menumbuh kembangkan kepekaan rasa serta memiliki daya kreatif cipta rupa. SMA N 1 Sukoharjo memiliki cara guna mengembangkan potensi peserta didik atas memberikan materi berinovasi dan bervariasi pada proses pembelajaran formal maupun ekstrakulikuler salah satunya mengadakan kolaborasi kegiatan workshop seni lukis atas pembelajaran berbasis video tutorial. Penelitian ini bermaksud guna memahami efektifitas penyampaian materi pada kegiatan workshop seni lukis dikelas ekstrakurikuler SMA N 1 Sukoharjo atas memakai media pembelajaran berbasis video tutorial. Analisis data yang dipakai selama penelitian ini merupakan deskripstif kualitatif atas memakai teknik analisis data model interaktif. Hasil dari penelitian ini menunjukkan bahwa penggunaan media berbasis video tutorial mampu merubah karya siswa dikelas ekstrakulikuler dari segi implementasi teknik maupun secara visual. Selain merubah hasil karya dampak lain dari kegiatan workshop materi seni lukis aqurael atas media berbasis video tutorial dikelas ekstrakurikuler seni rupa mampu merubah kondisi kegiatan didalam kelas menjadi lebih efektif dan efisien.
\end{abstract}

Kata Kunci: ekstrakurikuler, video tutorial, workshop, seni lukis

\section{ABSTRACT}

As educational institutions, schools can actually develop and improve students' academic and non-academic abilities. One of the non-academic education that is often taught in school is art education that can develop a sense sensitivity and have the creative power of such copyright. Sma $N 1$ Sukoharjo has a way to develop the potential of learners by providing innovating and varied materials in the formal and extracurricular learning process, one of which is holding a collaboration of painting workshop activities with video tutorial-based learning. This research aims to find out the effectiveness of material delivery in painting workshop activities in the extracurricular class of SMA N 1 Sukoharjo by using video tutorialbased learning media. The data analysis used during this study was qualitative descriptive using interactive model data analysis techniques. The results of this study show that the use of video-based media tutorials can change the work of students in extracurricular class in terms of technical implementation as well as visually. In addition to changing the results of other impact works from workshop activities of aqurael painting materials with video-based tutorial media in the extracurricular class of fine art can change the conditions of activities in the classroom to be more effective and efficient.

Keywords: Extracurricular, Video Tutorial, Workshop, Painting 


\section{Pendahuluan}

Pendidikan seni rupa di sekolah terutama ditujukan untuk mengembangkan kepekaan dan kreativitas dalam penciptaan visual, dan pendidikan merupakan proses diseminasi, termasuk transformasi pengetahuan, nilai dan keterampilan, baik di dalam maupun di luar sekolah, yang berlangsung seumur hidup. (kekal). proses), diturunkan dari generasi ke generasi (Siregar et al., 2022).

Pendidikan formal merupakan pendidikan yang secara sadar dirancang dan dilaksanakan menurut aturan yang ketat, seperti harus berlapis dan berkesinambungan (Adawiyah et al., 2017). Hadari Nawawi percaya bahwa dalam (Safrida, 2017), yaitu : Pendidikan formal merupakan usaha pendidikan yang sadar, terencana, terarah dan sistematis yang dilakukan melalui lembaga pendidikan yang disebut sekolah. Pendidikan formal merupakan pendidikan kedinasan yang bertingkat, seperti lembaga pendidikan dasar kedinasan dari kelas 1 sampai atas $6 \mathrm{ke}$ atas, sekolah menengah pertama, sekolah menengah atas, dan perguruan tinggi, yang diselenggarakan karena tanggung jawab pekerjaan guru kepada siswa. (Winarsih, 2019).

Pendidikan formal adalah pendidikan terstruktur yang mempunyai jenjang dalam jangka waktu tertentu, yang berlangsung dari sekolah dasar sampai perguruan tinggi, dan ruang lingkupnya selain bidang studi akademik umum, memiliki berbagai program dan lembaga khusus untuk pelatihan teknis di tempat (Yusuf, 1995). Selain atas aturan-aturan yang sudah dibuat secara terperinci dan ketat di dalam sekolah formal juga terdapat suatu kegiatan siswa guna menambah dan mengasah bakat, melalui kegiatan ekstrakurikuler, siswa mampu mengembangkan minat yang ada didalam diri serta menambah pengalaman belajar secara berbeda.

Sebagai lembaga pendidikan, sekolah berkewajiban tidak hanya mengembangkan dan meningkatkan kemampuan akademik siswa, tetapi juga mengembangkan dan meningkatkan kemampuan non akademik siswa (Jufri et al., 2019). Pada tataran nonakademik ini, sekolah harus menyediakan tempat tumbuh dan berkembangnya beragam bakat dan kreativitas, sehingga mampu memberdayakan siswa untuk menjadi manusia yang memiliki kebebasan berkreasi (Haryoko, 2012). Pengembangan potensi peserta didik terus dilakukan oleh guru mata pelajaran seni rupa SMAN 1 Sukoharjo atas memberikan materi yang berinovasi yang tidak hanya diberikan saat proses pembelajaran formal berlangsung tetapi juga diberikan saat kegiatan ekstrakurikuler atas berbagai kegiatan seperti mengundang pendidik lain guna mengadakan workshop materi sehingga kondisi kegiatan ekstrakurikuler mampu bervariasi dan tidak membosankan.

Seni lukis saat ini masih menjadi kegemaran anak muda tak terkecuali siswa sekolah menengah atas yang masih menggemari lukisan dari manual hingga digital yang banyak tersebar di website atau di sosial media seperti Instagram. Hal tersebut yang membuat banyak siswa SMAN 1 Sukoharjo membuat karya lukis secara manual dalam pelajaran seni rupa memakai berbagai jenis teknik dalam pembuatan karya, hal itulah yang mendorong tenaga pendidik ingin memberikan materi seni lukis cat air teknik aquarel pada kelas ekstrakurikuler seni rupa atas metode workshop dan media baru yang diharapkan mampu lebih 
merangsang jiwa kreativitas dan kesenirupaan siswa.

Pelaksanaan ekstrakurikuler seni rupa di SMAN 1 Sukoharjo dilaksanakan satu minggu sekali pada hari jumat setelah jam pembelajaran sekolah selesai, menurut pengampu kegiatan ekstrakurikuler seni rupa di SMAN 1 Sukoharjo pelaksanaan kegiatan ekstrakurikuler seni rupa difokuskan pada materi teknik seni lukis, seperti yang sering dilakukan merupakan melukis memakai cat air pada media kertas maupun media lain.

Berdasarkan pemaparan diatas maksud riset ini merupakan guna memahami efektifitas penyampaian materi pada kegiatan workshop seni lukis cat air dikelas ekstrakurikuler SMAN 1 Sukoharjo atas memakai media pembelajaran berbasis video tutorial.

\section{Metode Penelitian}

Jenis penelitian yang dipakai dalam penelitian ini merupakan deskriptif kualitatif (Sugiyono, 2016). Subjek dalam penelitian ini merupakan siswa ekstrakurikuler seni rupa SMA Negeri 1 Sukoharjo di JL. Pemuda No. 38 Jetis Sukoharjo.
Penelitian ini berfokus pada efektivitas proses penyampaian materi seni lukis atas memakai media berbasis video tutorial, sumber data yang diperoleh dari penelitian berasal dari informan, aktivitas dan peristiwa serta arsip dan dokumen, sedangkan guna pengumpulan data pada penelitian ini didapatkan melalui teknik wawancara, observasi, dan telaah dokumen atas memakai teknik analisis data model interaktif.

\section{Hasil Penelitian dan Pembahasan}

Proses komunikasi akan menentukan berhasil tidaknya proses belajar mengajar. Proses komunikasi melibatkan partisipan dan saluran komunikasi. Peran saluran komunikasi akan sangat penting. Saluran ini disebut media. Menurut (Fausih \& Danang, 2015) Media merupakan bagian integral dari komunikasi, yaitu sebagai penyampai pesan dari komunikator ke komunikator. Berdasarkan pengertian tersebut dapat dikatakan bahwa proses belajar merupakan proses komunikasi. Proses belajar pada hakikatnya adalah proses komunikasi, penyampaian informasi dari pengenalan kepada penerima.

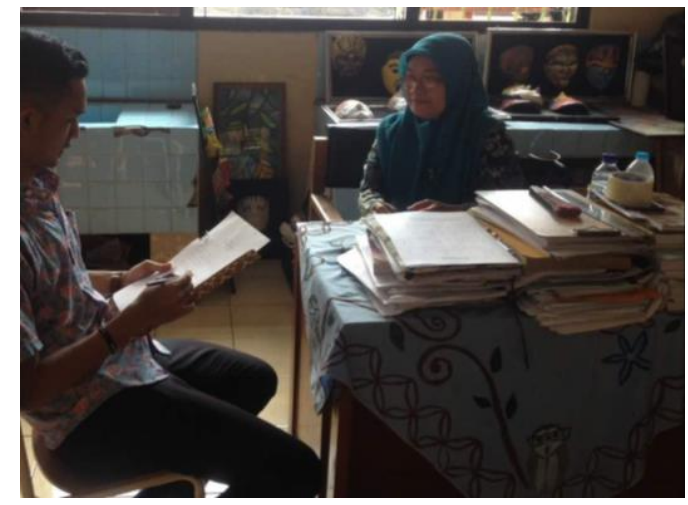

Gambar 1.

Proses wawancara awal atas pengampu kelas ekstrakurikuler

(Dokumentasi: Siswa) 
Tahapan awal yang dilakukan peneliti sebelum menyampaikan materi workshop atas memakai video tutorial merupakan observasi awal di kelas ekstrakurikuler, selanjutnya wawancara atas pihak pengampu mengenai efektifitas kegiatan ekstrakurikuler yang sudah terjadi sebelumnya, setelah mendapat data dan hasil karya siswa kemudian peneliti mulai menelaah hasil karya tersebut atas memakai prinsip-prinsip seni rupa yang meliputi: (1)Titik, (2)Garis, (3)Bidang, (4)Bentuk, (5)Tekstur, (6)Warna, (7)Gelap terang, (8)Ruang kedalaman.

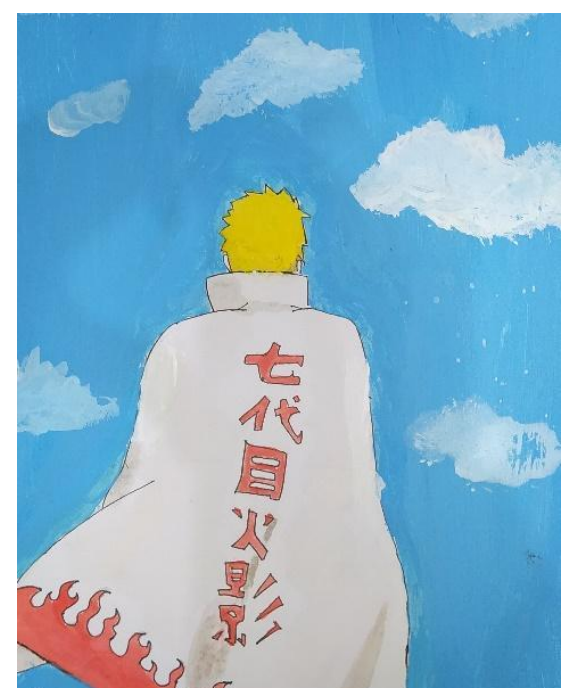

\section{Gambar 2. Karya siswa ekstrakurikuler seni lukis aquarel}

(Dokumen kelas ekstrakurikuler)

Hasil telaah dan analisis karya tersebut atas memakai prinsip seni rupa serta jenis teknik aquarel yang ada didapatkan fakta bahwa sebelumnya siswa kelas ekstrakurikuler belum memahami benar teknik dalam berkarya seni lukis aquarel (Ambarita, 2020). Bisa dilihat dari goresan cat serta teknik dalam pencampuran warna guna teknik aquarel sangatlah berbeda, secara umum penggunaan teknik diatas yaitu teknik plakat, maka keputusan pengampu kelas ekstrakurikuler tersebut dirasa benar atas cara mengundang pendidik lain guna diadakan workshop mengenai seni lukis aquarel agar mampu meningkatkan efektifitas kelas ekstrakurikuler serta pemahaman siswa terhadap materi menjadi maksimal yang berdampak ke hasil karya siswa kedepannya.
Selanjutnya dalam tahap awal saat mengadakan workshop di lapangan peneliti mengenalkan berbagai jenis teknik dalam melukis atas media cat air atas cara penjelasan secara konvensional serta memperlihatkan hasil karya sembari menyebutkan jenis teknik yang dipakai, dalam berkarya seni lukis aquarel terdapat bermacam cara dasar yang mesti dipahami dan dikuasai antara lain : (1) Sapuan dasar, (2) Sapuan gradasi satu warna, (3) Sapuan gradasi warna, (4) Wet on wet, (5) Wet on dry, (6) Sapuan kering, (7) Tepian halus.

Setelah dirasa cukup dalam pemberian materi secara konvensional selanjutnya peneliti memulai workshop seni lukis aquarel atas memakai media berbasis video tutorial, dimulai dari pengenalan tools dan pengoprasian media 
CAKRAWALA - Repositori IMWI | Volume 4, Nomor 2, Oktober 2021 p-ISSN: 2620-8490; e-ISSN: 2620-8814

tersebut agar siswa kelas ekstrakurikuler lebih mudah saat memakainya.

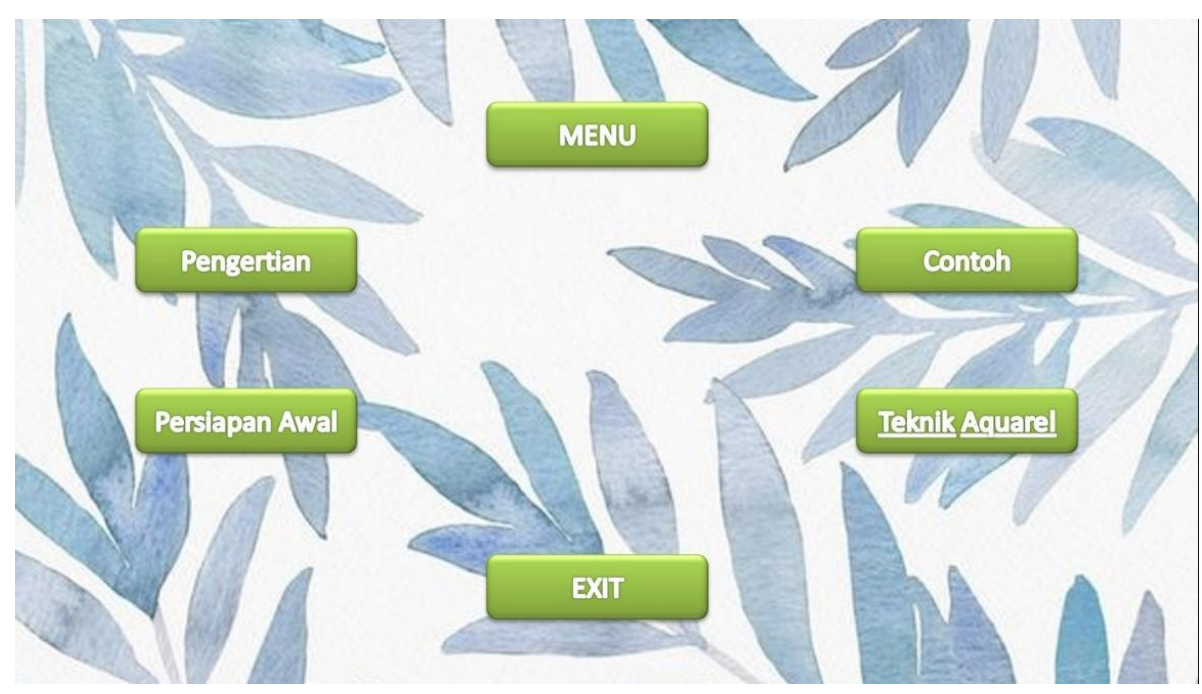

Gambar 3. Menu Utama Media Video tutorial

(Dokumentasi: Faizal, Screen Capture )

Gambar screen capture di atas merupakan menu utama yang ditampilkan pada media berbasis video tutorial.

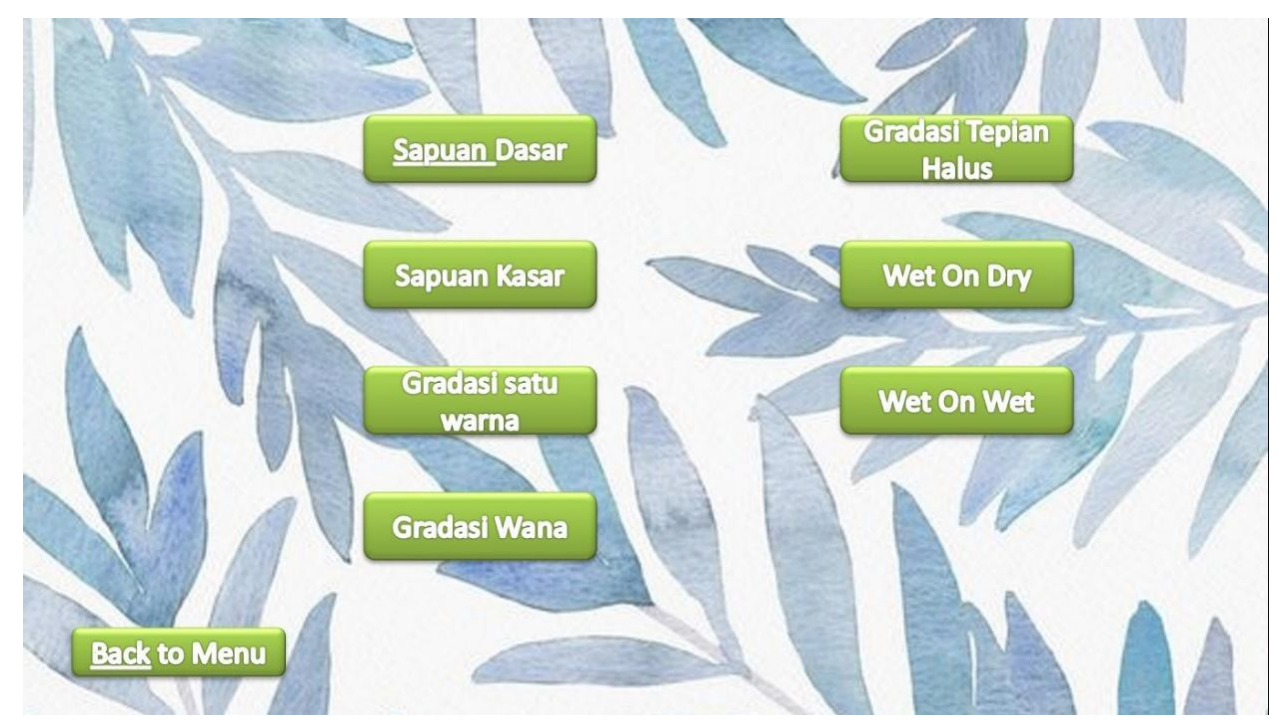

Gambar 4. Jenis teknik yang terdapat pada media

(Dokumentasi: Faizal, Screen Capture )

Gambar screen capture di atas merupakan menu yang menampilkan jenis- jenis yang terdapat pada media berbasis video tutorial. 


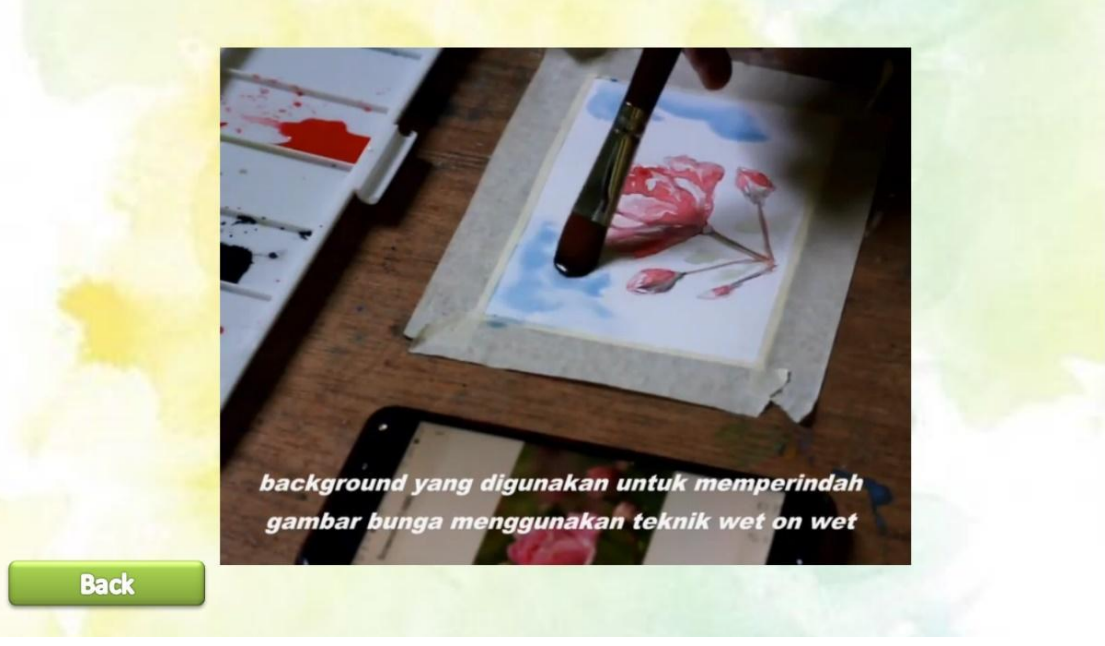

\section{Gambar 5. Salah satu jenis teknik yang terdapat pada media}

(Dokumentasi: Faizal, Screen Capture )

Video diatas menampilkan contoh teknik wet on wet atas membuat background bunga yang sebelumnya sudah dikerjakan atas teknik wet on dry, atas adanya media berbasis video tutorial ini diharapkan mampu memberikan pengalaman siswa secara visual agar siswa mampu berimajinasi dan mengimplementasikan teknik yang sebelumnya sudah dipelajari, atas contoh yang real dan dikemas atas teks serta suara yang jelas maka akan mempermudah siswa

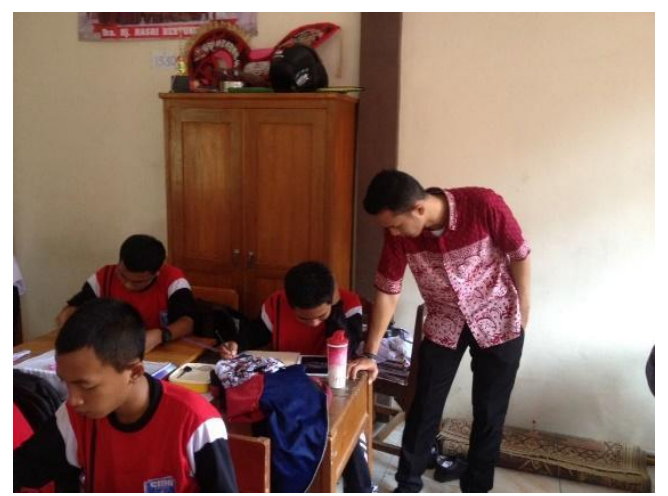

Gambar 6. Proses berkarya siswa kelas ekstrakurikuler

(Dokumentasi: Guru pengampu)

Berdasarkan pengamatan dan observasi selama kelas ekstrakurikuler seni lukis aquarel berlangsung atas memakai media berbasis video tutorial terasa sangat

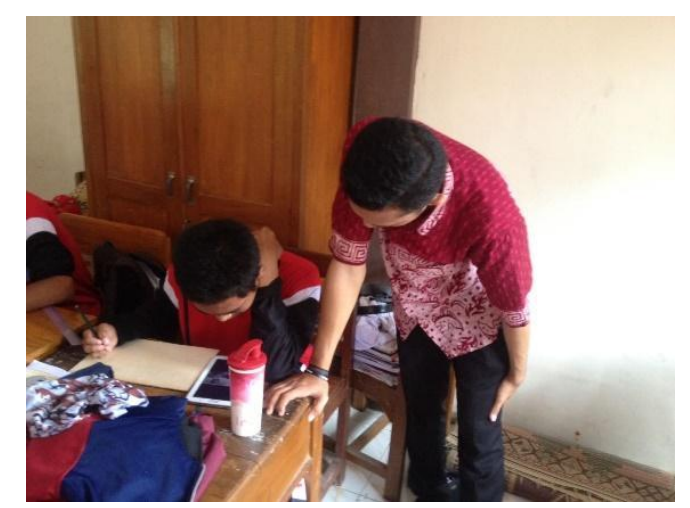

dalam memahami instruksi saat memakai tekniknya.

Setelah menerangkan tools dan cara pengoprasian media berbasis video tutorial selanjutnya peneliti mempersilahkan siswa guna memulai membuat sketsa atas didampingi media tersebut, selain didampingi media siswa kelas ekstrakurikuler juga didampingi peneliti guna mendeskripsikan kegiatan dan aktivitas yang terjadi di dalam kelas tersebut. 
berikut ini salah satu contoh karya siswa dan menerima workshop ini atas baik. yang mampu dikatakan mampu memahami

\section{Gambar 7. Salah satu sampel karya siswa setelah workshop}

(Dokumentasi: Faizal )

Karya di atas merupakan salah satu sampel karya yang diambil setelah dilakukan workshop seni lukis aquarel atas memakai media berbasis video tutorial, mampu dilihat dari segi pencampuran cat yang dipakai serta penggunaan teknik yang diimplementasikan siswa sudah memenuhi kaidah-kaidah dalam berkarya seni lukis aquarel, sejalan atas ungkapan (Nugroho, 2020), Cat air adalah campuran pigmen arab gum yang sangat halus (getah yang larut dalam air dari pohon akasia), gliserin (untuk menjaga warna tetap lembab), dan bahan pembasah (untuk membuat cat lebih mudah mengalir). Ketika pigmen ini dilarutkan dalam air pada palet dan disikat di atas kertas, pigmen ini tampak transparan sebagai ciri medium. Pelukis cat air murni tidak menggunakan cat putih karena air digunakan untuk mencerahkan warna, dan warna putih kertas digunakan untuk memantulkan cahaya melalui sapuan kuas.

Perkembangan teknologi Pendidikan pada gilirannya menumbuhkan perkembangan baru di bidang pendidikan (Haryoko, 2012). Ide-ide dan penemuanpenemuan baru muncul, termasuk penggunaan multimedia pendidikan. Menurut Binanto (2013), multimedia adalah kombinasi teks, seni, suara, animasi, dan video yang dikirimkan kepada Anda melalui komputer atau elektronik atau digital. Menurut para ahli, multimedia dapat dirancang sebagai media pembelajaran yang menggabungkan teks, seni, suara, animasi, dan video.

Dari paparan di atas mampu disimpulkan bahwa workshop yang dilakukan peneliti yang berkolaborasi atas pengampu kelas ekstrakurikuler yang memanfaatkan media berbasis video tutorial berhasil dilaksanakan karena mampu dipakai siswa guna mengulang materi dan dipakai guna belajar mandiri sehingga proses belajar menjadi lebih efektif.

Selanjutnya menurut pendapat guru SMAN 1 Sukoharjo saat dilakukan wawancara mengungkapkan bahwa media berbasis video tutorial sangat tepat dipakai sebagai alat penyampaian materi secara 
kelompok maupun individu. Karena dukungan teknis yang kuat mampu mendorong siswa guna belajar dan mengajar secara mandiri lebih berdaya guna,tepat guna dan efektif. Dari argumentasi diatas yang diharapkan peneliti media berbasis video tutorial yang dipakai dalam workshop seni lukis aquarel mampu dipakai secara luas sehingga berdampak terhadap proses berkarya siswa sekolah formal maupun non formal.

\section{Kesimpulan}

Kendala keterbatasan media dan waktu jam pelajaran yang terbatas mendorong sekolah memberikan kegiatan ekstrakurikuler sebagai wadah penyaluran bakat bagi siswa yang memiliki keterbukaan akan materi dan solusi pengayaan kompetensi dalam bidang seni rupa, hal tersebut yang menarik guna diberikan materi workshop atas cara penyampaian melalui media video berbasis tutorial yang ideal sebagai akses siswa guna belajar seni lukis aquarel atas efektif dan efisien. Setelah video berbasis tutorial cocok guna dipakai dalam kelas ekstrakurikuler yang didukung atas hasil pengamatan kegiatan dan hasil karya siswa yang meningkat maka video tutorial tersebut dibagikan ke pengampu kelas ekstrakurikuler atas tujuan agar mampu disampaikan kembali di kelas ekstrakurikuler selanjutnya dan menjadi panduan guna belajar mandiri tanpa tergantung pada pembelajaran dikelas dan di sekolah, atas memanfaatkan video berbasis tutorial siswa mampu memahami prinsip berkarya seni lukis teknik aquarel.

\section{Referensi}

Adawiyah, R., Wibowo, Y. S., \& Kartika, Y. (2017). Pendidikan yang berdaya saing. Prosiding Seminar Nasional Pendidikan FKIP, 1(2).

Ambarita, I. B. (2020). Potret Keunggulan Ekstrakurikuler Seni Lukis MIN 3 Ponorogo atas Pengembangan Bakat Minat Siswa. IAIN Ponorogo.

Binanto, I. (2013). Kajian metode-metode pengembangan perangkat lunak multimedia. Jurnal Penelitian, 17(1).

Fausih, M., \& Danang, T. (2015). Pengembangan media e-modul mata pelajaran produktif pokok bahasan "instalasi jaringan lan (local area network)" untuk siswa kelas xi jurusan teknik komputer jaringan di smk nengeri 1 labang bangkalan madura. Jurnal Unesa, 1(01), 1-9.

Haryoko, S. (2012). Efektivitas pemanfaatan media audio-visual sebagai alternatif optimalisasi model pembelajaran. Jurnal Edukasi Elektro, 5(1).

Jufri, J., La Fua, J., \& Nurlila, R. U. (2019). Pendidikan Lingkungan Di Sekolah Dasar Negeri 1 Baruga Kota Kendari. Al-TA'DIB: Jurnal Kajian Ilmu Kependidikan, 164-181.

Nugroho, M. F. A. (2020). pengembangan media pembelajaran video tutorial melukis teknik aquarel di sma negeri 3 surakarta tahun ajaran 2020. senada (Seminar Nasional Manajemen, Desain Dan Aplikasi Bisnis Teknologi), 3, 318-323.

Safrida, S. (2017). pengaruh pendidikan formal dan status sosial ekonomi masyarakat terhadap prestasi belajar siswa di smp negeri 25 medan. Tijarah: Jurnal Ekonomi Dan Bisnis, 2(14).

Siregar, R. S., Saputro, A. N. C., Saftari, M., Panggabean, N. H., Simarmata, 
p-ISSN: 2620-8490; e-ISSN: 2620-8814

J., Kholifah, N., Fahmi, A. I., Subakti, H., \& Harianja, J. K. (2022). Konsep Dasar Ilmu Pendidikan. Yayasan Kita Menulis.

Sugiyono. (2016). Metode Penelitian Pendidikan (Pendekatan Kuantitatif, Kualitatif, dan $R \& D)$. ALFABETA, CV.
WINARSIH, D. P. N. U. R. (2019). Pengaruh Latar Belakang Pendidikan Orangtua Dan Lingkungan Sosial Terhadap Minat Siswa Kelas Ix Melanjutkan Sekolah Di Smpn 1 Rejotangan Tulungagung.

Yusuf, E. M. (1995). Administrasi Supervisi Pendidikan. Malang: IKIP. 